\title{
ORIGINAL
}

\section{Causes and predictors of early mortality in patients treated with left ventricular assist device implantation in the European Registry of Mechanical Circulatory Support (EUROMACS)}

Sakir Akin ${ }^{1,2}$, Osama Soliman³, Theo M. M. H. de By ${ }^{4}$, Rahatullah Muslem¹, Jan G. P. Tijssen ${ }^{5,6}$, Felix Schoenrath', Bart Meyns ${ }^{8}$, Jan F. Gummert ${ }^{9}$, Paul Mohacsi ${ }^{10}$ and Kadir Caliskan ${ }^{1 *}$ (D) on behalf of the EUROMACS investigators

() 2020 The Author(s)

\begin{abstract}
Purpose: The aim of the study was to analyze early mortality after continuous-flow left ventricular assist device (LVAD) implantation which remains high.

Methods: We analyzed consecutive $(n=2689)$ patients from the European Registry for Patients with Mechanical Circulatory Support (EUROMACS) undergoing continuous-flow LVAD implantation. The primary outcome was early (<90 days) mortality. Secondary outcomes were differential causes of early post-operative death following LVAD implantation.
\end{abstract}

Results: Univariable and multivariable analysis as well as regression analysis were used to examine determinants and differential causes of early (<90 days) mortality after LVAD implantation. During the first 90 days, 2160 (80\%) patients were alive with ongoing LVAD support, 40(2\%) patients underwent heart transplantation, and 487(18\%) deceased. The main causes of early death were MOF (36\%), sepsis (28\%), cardiopulmonary failure (CPF; 10\%), CVA (9\%), and rightsided heart failure (RHF, 8\%). Furthermore, MOF and sepsis are 70\% of causes of death in the first week. Independent clinical predictors of early death were age, female sex, INTERMACS profile 1 to 3, and ECMO. Laboratory predictors included elevated serum creatinine, total bilirubin, lactate, and low hemoglobin. Furthermore, hemodynamic predictors included elevated RA-to-PCWP ratio, pulmonary vascular resistance, and low systemic vascular resistance. Longer total implantation time was also independent predictor of early mortality. A simple model of 12 variables predicts early mortality following LVAD implantation with a good discriminative power with area under the curve of 0.75 .

Conclusions: In the EUROMACS registry, approximately one out of five patients die within 90 days after LVAD implantation. Early mortality is primarily dominated by multiorgan failure followed by sepsis. A simple model identifies important parameters which are associated with early mortality following LVAD implantation.

Keywords: Left ventricular assist device, Mortality, Intensive care, Causes, Predictors

\footnotetext{
${ }^{*}$ Correspondence: k.caliskan@erasmusmc.nl

${ }^{1}$ Thoraxcenter, Department of Cardiology, Erasmus MC University

Medical Centre Rotterdam, Dr. Molewaterplein 40, 3015 GD, Rotterdam,

The Netherlands

Full author information is available at the end of the article

Sakir Akin and Osama Soliman have contributed equally.
}

\section{亚




\section{Introduction}

Continuous-flow left ventricular assist devices (LVADs) are increasingly used for treating patients with endstage heart failure as a bridge to cardiac transplantation (HTx) or as a destination therapy (DT). Compared with medical therapy, LVAD implantation has reduced death and improved quality of life [1-3]. Current state-of-theart devices are promising in terms of improved survival and lower morbidity rates [4]. However, early post-LVAD mortality remains high [5-8]. Furthermore, causes and determinants of death following LVAD implantation are not well described for the European population. In small series, high post-LVAD mortality is associated with acute kidney injury (AKI) and multi-organ failure $[9,10]$. There are few data on predictors of early ICU death ( $\leq 90$ days) after LVAD implantation [11].

Therefore, we aimed to investigate the causes of death early after LVAD implantation. Furthermore, we sought to explore predictors of early death using multivariate analysis. The preliminary result of this study is partly presented at the scientific sessions of the European Society of Cardiology Congress [12].

\section{Methods}

\section{Study population}

All consecutive patients treated with mainstream continuous-flow LVAD devices (i.e., HeartMate II, HeartWare, and HeartMate 3) from EUROMACS, a Registry of the European Association for Cardio-Thoracic Surgery, from January 2006 until May 2017 were included. All participating hospitals sign a contract with the EUROMACS Registry. In the contract, it is agreed that patients are sufficiently informed about the treatment that they are to undergo, including the risk of complications and mortality. The Registry contains data for scientific analyses, and is aimed at improving care of patients with endstage heart failure (HF) who need mechanical circulatory support [13]. All relevant clinical, echocardiographic, hemodynamic, and laboratory characteristics were prospectively collected by participating EUROMACS sites and entered into an electronic database (see appendix Table 1 for the list of EUROMACS sites and investigators (alphabetical according to country). To ensure the best quality of data and to exclude the underreporting of poor outcomes, the EUROMACS Registry applies several methods. Incoming data are analyzed on a regular basis. Individual hospitals are approached, and guidance is offered to complete or correct their data. Entries are adapted to adhere to the standard. Twice a year, each center receives a file in which an overview of patients whose statuses need to be updated and whose changes/ answers have to be monitored is presented. Statistical

\section{Take-home message}

Eighteen percent of patients in the EUROMACS registry died within 90-days following LVAD implantation.

Early mortality after LVAD implantation is primarily dominated by multiorgan failure followed by sepsis.

A simple model of 12 variables predicts early mortality following LVAD implantation with a good discriminative power with area under the curve of 0.75 .

consistency and plausibility checks are performed, and the records containing the inconsistent data of the participating centers are identified. Data that are not plausible require checking and confirmation by the participating centers. Details of the Registry and data collection are described elsewhere [13]. This study was approved by the local institutional review committee and all subjects provided informed consent.

\section{Study outcome}

We defined early mortality as death within 90 days after LVAD implantation. The EUROMACS registry protocol mandates sites to report death using a list of 17 causes of death as follows: multi-organ failure (MOF), cerebro-vascular accident (CVA), sepsis, infection, bleeding, cardiopulmonary failure (CPF), right-sided heart failure (RHF), device failure, lung failure, myocardial infarction, suicide, cancer, left heart failure, pulmonary artery embolism, trauma, other causes of death, and unknown cause of death. MOF implies usually two or more organs' dysfunction at the same time. We combined sepsis and infection into sepsis as main cause of death. Similarly, cardiopulmonary failure, left heart failure, lung failure, pulmonary artery embolization, and myocardial infarction into cardiopulmonary failure (CPF). Right-sided heart failure (RHF) as directly related to death was documented independently, when RHF does not lead to MOF or sepsis $[14,15]$. Therefore, we created eight dominant causes of death including sepsis, MOF, CVA, CPF, bleeding, RHF, device failure, and others. Other causes of death included cancer, suicide, trauma, and all other than main causes of death.

\section{Potential predictors of early mortality}

We examined potential pre-operative characteristics as well as surgical and cardiopulmonary bypass (CPB) time for the association with early mortality. Pre-operative clinical data included age, gender, body surface area, body mass index, and blood type, HF etiology, NYHA functional profile, and INTERMACS profile were taken into account [16]. The pre-operative use of $\geq 3$ intravenous inotropes as well as the use of vasopressors were included. Furthermore, LVAD device strategy such as DT, 
use of intra-aortic balloon pump (IABP), and extracorporeal membrane oxygenator (ECMO) were additionally included. Pre-operative echocardiographic characteristics were recorded and analyzed in accordance with published guidelines $[17,18]$ including tricuspid annular plane systolic excursion (TAPSE), RV dysfunction on visual score, LV ejection fraction (LVEF), and mitral, aortic, and tricuspid valvular regurgitation. Median duration of echocardiographic data collection before LVAD surgery was 6 days. Severity of valvular regurgitation was graded as none, trivial, mild, moderate, and severe according to published guidelines $[19,20]$.

Hemodynamic predictors included heart rate, systolic and diastolic blood pressure, as well as Swan-Ganz recordings. The latter included systolic, diastolic and mean pulmonary artery (PA) pressure, right atrial (RA) pressure, pulmonary capillary wedge pressure (PCWP), pulmonary (PVR) and systemic (SVR) vascular resistance, and cardiac index. The PVR is calculated as transpulmonary gradient (TPG) divided by the cardiac output (CO), which has a normal value of $<3$ Wood units (or 240 dynes $\cdot \mathrm{sec} \cdot \mathrm{cm}^{-5}$ ). TPG was calculated as the difference between the PA mean pressure and PCWP. The ratio of RA to PCWP and PA pulsatility index (PAPi) [21] were also calculated. The RV systolic work index (RVSWI) was calculated as RV stroke volume index $\times$ (mean PA pressure - central venous pressure) $\times 0.0136$ expressed in $\mathrm{gm} / \mathrm{m}^{2} /$ beat were calculated. The factor 0.0136 was used to covert pressure $(\mathrm{mmHg})$ into work $\left(\mathrm{g} / \mathrm{m}^{2}\right)$. Normal values are $5-10 \mathrm{~g} / \mathrm{m}^{2} /$ beat.

Laboratory characteristics included serum sodium and potassium levels, renal function parameters including blood urea nitrogen, serum creatinine levels, and liver function parameters including AST, LDH, total bilirubin, and serum albumin level. In addition, white blood count, platelets count, INR, APTT, lactate, and hemoglobin levels were also included.

\section{Statistical analysis}

Patient characteristics are described as means (standard deviation $[\mathrm{SD}]$ ) or medians (interquartile range [IQR]) for continuous variables and frequency (percentage) for categorical variables. Differences between patient groups are evaluated for continuous variables by the Student $t$ tests (Gaussian distribution) or the non-parametric Mann-Whitney $U$ tests (non-Gaussian distribution) and the categorical variables using the Chi-square test.

Univariate logistic regression analysis was applied to relate a broad range of pre-operative parameters with the study outcome, including demographics, clinical, medications, echocardiographic, hemodynamic, and laboratory characteristics. Variables with a $p$ value $<0.20$ entered the multivariate stage, and a multivariate regression model was constructed to predict early mortality following LVAD implantation, applying the stepwise forward method, with a $p=0.05$ model-entry criterion.

For the main causes of death, we calculated and reported the frequencies for early mortality in timebased analysis beginning from the day of implantation till 30 days and between 30 and 90 days. We reported the cumulative early mortality. Multiple imputations were used to account for randomly missing values after examining the pattern of missing values as described before [14]. We accepted the missing data for $<20 \%$ of in the entire population. The goodness-of-fit of the logistic regression model was measured in terms of its calibration. Calibration, which measures the ability of the model to fit the data, was tested with the Hosmer-Lemeshow statistic.

A two-tailed $p<0.05$ was considered statistically significant, and all statistics were undertaken using the SPSS statistics version 24 (IBM corporation, NY, USA), MedCalc (Statistical MedCalc Software, Ostend, Belgium), and the R-statistical package.

\section{Results \\ Study cohort}

Between January 1, 2006, and May 31, 2017, a total of 2988 adult patients who underwent continuous-flow LVAD implantation with mainstream devices (HeartWare, HeartMate II, or HeartMate 3) were included. We excluded patients missing data about the brand type of LVAD $(n=35)$ and missing follow-up data $(n=264)$ (Fig. 1). The final study population comprised 2689 patients with a mean age of $53 \pm 13$ years and $472(18 \%)$ women (Table 1$)$; the majority were Caucasians $(66 \%$, $n=1785)$. The main etiology of HF was non-ischemic $(67 \%, n=1807)$. The main indications for LVAD implantation were bridge to candidacy $(44 \%, n=1001)$, followed by BTT $(29 \%, n=655)$. Mainstream devices were HeartWare ${ }^{\circledR}$ HVAD as the most used LVAD brand (51\%, $n=1369)$, followed by HeartMate $\mathrm{II}^{\circledR}(43 \%, n=1167)$ and HeartMate $3^{\circledR}(6 \%, n=153)$.

\section{Post LVAD outcome}

During follow-up duration of 90 days, out of 2689 patients, 487 (18\%) were deceased; $40(2 \%)$ were transplanted; in $2(0.1 \%)$, the device was explanted; and 2160 (80\%) were alive on LVAD support (Fig. 1). Differences in key baseline and peri-operative characteristics between survivors and non-survivors are shown (Table 1).

\section{Time course of death after LVAD implantation}

Overall, primary causes of death were sepsis (28\%), MOF (26\%), and CVA (15\%). Furthermore, MOF (36\%), sepsis $(28 \%)$, and CPF (10\%) were the main primary 


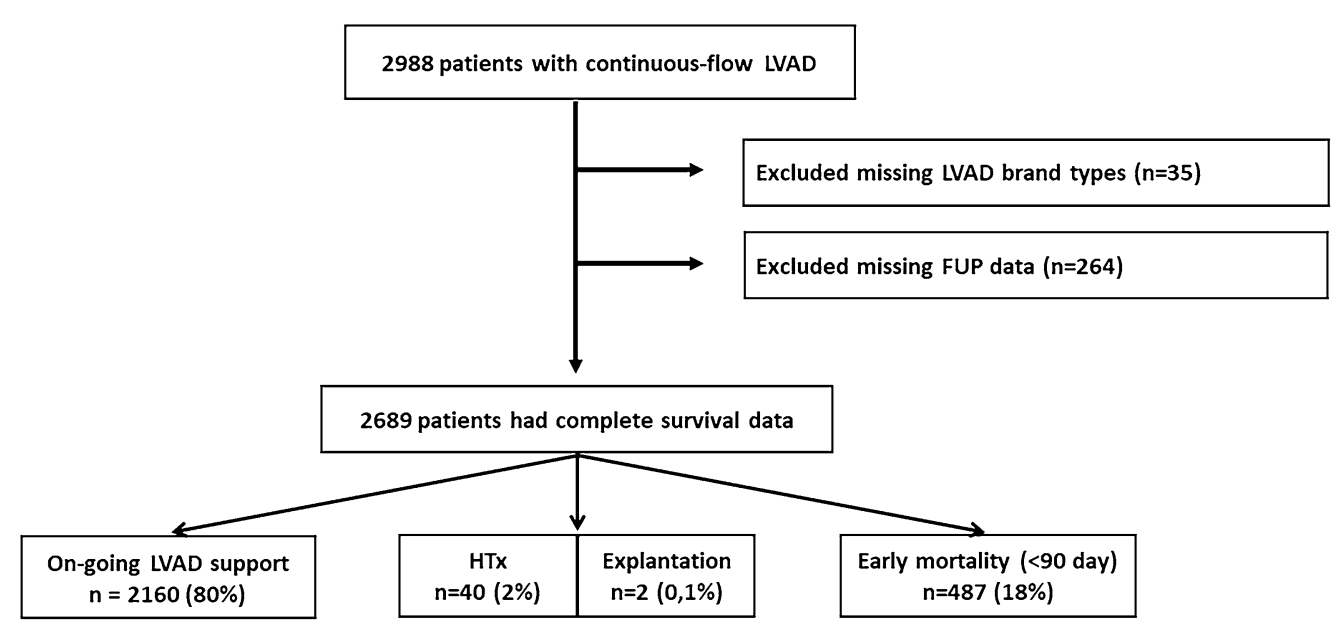

Fig. 1 Flowchart of the study population. This flowchart describes the outcome in total population of EUROMACS over follow-up of 90 days. EUROMACS The European Registry for Patients with Mechanical Circulatory Support, LVAD left ventricular assist device

causes of death followed by CVA (9\%) and RHF (8\%) in the early ( $\leq 90$ days) after LVAD implantation (Fig. 2).

\section{Differential causes of death within 90 days following LVAD implantation}

In-depth daily or weekly analysis of the differential causes of death in the early 90 days following LVAD implantation revealed MOF as the main cause of death in $40-50 \%$ the first 2 weeks and decreased to approximately $10 \%$ of total causes of death thereafter. In contrast sepsis is seen in day one as $10 \%$ of causes of death, increased to $20-40 \%$ thereafter. CPF occurred in $20 \%$ at the day of LVAD implantation and decreased to $5 \%$ or less thereafter. CVA was seen as $20 \%$ of causes of death on the day of LVAD implantation, 5-10\% between day 1 to 90 days. Bleeding as a cause of death was seen in $20 \%$ of causes of death during day one after LVAD implantation, $<5 \%$ between day 2 and 90 days. RHF as a cause of death was seen in approximately $20 \%$ of causes of death during day 1 after LVAD implantation. Device failure was not seen as a cause of death in the first 90 days.

As seen on Fig. 2, only nine subjects in the study died on the day of operation and 16 subjects died in the first day after the operation. Known causes of death on the operation day were cerebro-vascular accident in one patient, multi-organ failure in two, cardiopulmonary failure in one, and other cause of death in one patient,

In the day after LVAD implantation, known causes of death were MOF in eight patients, RHF in three, bleeding in three, CVA in one, and sepsis in one were seen.

\section{Predictors of early mortality post-LVAD}

Univariate exploratory analysis as well as multivariable model of the independent predictor of early mortality following LVAD implantation are seen in Tables 1 and 2. Exploratory univariate logistic regression analysis for early mortality following LVAD implantation yielded 49 potential covariates $(p<0,20)$ out of 59 tested variables, as clinical, medication, laboratory, echocardiographic, hemodynamic, and operative covariates (Table 2). Independent clinical predictors of early death were age (OR 1.028, 95\% CI 1.018-1.038) female sex (OR 1.339, 95\% CI 1.003-1.788), INTERMACS profile 1 to 3 (OR 1.500, 95\% CI 1.121-2.007), and ECMO (OR 1.989, 95\% CI 1.431-2.765). Laboratory predictors included elevated serum creatinine (OR 1.003, 95\% CI 1.002-1.005), total bilirubin (OR 1.193, 95\% CI 1.116-1.275), lactate (OR 1.011, 95\% CI 1.003-1.019), and low hemoglobin (OR 0.908, 95\% CI 0.858-0.961). Furthermore, hemodynamic predictors included elevated RA-to-PCWP ratio (OR 1.740, 95\% CI 1.292-2.344), pulmonary vascular resistance (OR 1.089, 95\% CI 1.044-1.135), and low systemic vascular resistance (OR 0.974, 95\% CI $0.957-$ 0.992). Longer total implantation time (OR 1.003, 95\% CI 1.002-1.004) was also independent predictor of early mortality (Table 3 ).

ROC analysis of the two multivariable models yielded a predictive discriminative value of 0.75 (Fig. 3). Furthermore, the model had a good calibration by the Hosmer-Lemeshow statistic (Chi-square value, 8.38, $p$ value: 0.40 ). 
Table 1 Baseline and peri-operative characteristics of patients undergoing continuous-flow LVAD implantation

\begin{tabular}{|c|c|c|c|c|}
\hline Variables & $\begin{array}{l}\text { Total population } \\
(N=2689)\end{array}$ & $\begin{array}{l}\text { Survivors } 90 \text { days } \\
(n=2202)\end{array}$ & $\begin{array}{l}\text { Non-survivors } 90 \text { days } \\
(n=487)\end{array}$ & $p$ value \\
\hline \multicolumn{5}{|l|}{ Demographics } \\
\hline Age, year & $53 \pm 13$ & $52 \pm 12$ & $55 \pm 13$ & $<0.001$ \\
\hline Gender (Female), $n(\%)$ & $472(18)$ & $373(17)$ & $99(20)$ & 0.08 \\
\hline Body surface area, $\mathrm{m}^{2}$ & $1.96 \pm 0.23$ & $1.96 \pm 0.23$ & $1.96 \pm 0.26$ & 0.66 \\
\hline Body mass index, $\mathrm{kg} / \mathrm{m}^{2}$ & $26.1 \pm 5$ & $26 \pm 4.8$ & $26.7 \pm 5.6$ & 0.01 \\
\hline Ischemic etiology, n (\%) & $882(33)$ & $704(32)$ & $178(37)$ & 0.06 \\
\hline Blood type $0, n(\%)$ & $1010(38)$ & $823(37)$ & $187(38)$ & 0.68 \\
\hline INTERMACS class, $n(\%)$ & & & & $<0.001$ \\
\hline 1 & $297(11)$ & $182(8)$ & $115(24)$ & \\
\hline 2 & $854(32)$ & $663(30)$ & 191 (39) & \\
\hline 3 & $693(26)$ & $610(28)$ & $83(17)$ & \\
\hline$\geq 4$ & $737(27)$ & $653(30)$ & $84(17)$ & \\
\hline IABP, \% & $246(9)$ & $185(8)$ & $61(13)$ & 0.01 \\
\hline VA-ECMO, \% & $249(9)$ & $101(5)$ & $148(30)$ & $<0.001$ \\
\hline NYHA functional class, $n(\%)$ & & & & 0.001 \\
\hline III & $838(31)$ & $715(32)$ & $123(25)$ & \\
\hline IV & $1110(41)$ & $875(40)$ & $235(48)$ & \\
\hline \multicolumn{5}{|l|}{ Intravenous medication, $n$ (\%) } \\
\hline Use of vasopressors & $574(21)$ & $381(17)$ & $193(40)$ & $<0.001$ \\
\hline Use of inotropes $\geq 3$ & $340(13)$ & $243(11)$ & $97(20)$ & $<0.001$ \\
\hline \multicolumn{5}{|l|}{ Laboratory } \\
\hline Serum creatinine, $\mathrm{mg} / \mathrm{dL}$ & $1.17[0.96-1.5]$ & $1.15[0.95-1.43]$ & $1.29[1.06-1.84]$ & $<0.001$ \\
\hline $\mathrm{BUN}, \mathrm{mg} / \mathrm{dL}$ & $48[34-74]$ & $46[32-68]$ & $63[40-97]$ & $<0.001$ \\
\hline $\mathrm{AST}, \mathrm{U} / \mathrm{L}$ & $31[22-64]$ & $30[21-53]$ & $46[25-187]$ & $<0.001$ \\
\hline $\mathrm{LDH}, \mathrm{U} / \mathrm{L}$ & 340 [257-489] & $334[252-474]$ & $364[271-591]$ & $<0.001$ \\
\hline Total bilirubin, mg/dL & $1.32[0.83-2.05]$ & $1.27[0.8-1.9]$ & $1.64[1.1-2.6]$ & $<0.001$ \\
\hline $\mathrm{WBC}, 10^{9} / \mathrm{mL}$ & $8.2[6.5-10.7]$ & 8 [6.4-10.3] & $9.3[6.9-12.6]$ & $<0.001$ \\
\hline Platelets, $1000 / \mathrm{mL}$ & 207 [158-252] & 211 [170-254] & 179 [116-240] & $<0.001$ \\
\hline INR & $1.3[1.1-1.6]$ & $1.24[1.1-1.5]$ & $1.39[1.2-1.8]$ & $<0.001$ \\
\hline aPTT, sec & $39[32-47]$ & $39[32-46]$ & $42[34-53]$ & $<0.001$ \\
\hline Lactate, $\mathrm{mmol} / \mathrm{L}$ & $1.5[1.1-2.3]$ & $1.4[1-2.1]$ & $1.6[1.1-3.5]$ & $<0.001$ \\
\hline Albumin, mg/dL & $3.9[3.3-5.2]$ & $3.9[3.4-5.2]$ & $3.6[3.2-4.7]$ & $<0.001$ \\
\hline Hemoglobin, g/dL & $12.1[10.5-13.9]$ & $12.4[10.8-14]$ & $10.9[9.8-12.7]$ & $<0.001$ \\
\hline \multicolumn{5}{|l|}{ Hemodynamic } \\
\hline Heart rate, beats/min & 85 [74-98] & 84 [74-98] & 88 [75-101] & 0.01 \\
\hline Diastolic BP, mmHg & $65[59-71]$ & 65 [60-72] & $62[55-70]$ & 0.07 \\
\hline Systolic BP, mmHg & 100 [90-110] & 100 [90-110] & $100[88-110]$ & 0.07 \\
\hline RA pressure, $\mathrm{mmHg}$ & $11[8-15]$ & $10[7-14]$ & $13[9-17]$ & $<0.001$ \\
\hline PCWP, mmHg & 24 [18-29] & $24[29]$ & $25[29]$ & 0.32 \\
\hline PAP systolic & $52[41-63]$ & $53[41-63]$ & 52 [40-62] & 0.37 \\
\hline PAP diastolic & 26 [20-32] & $26[20-32]$ & $26[21-32]$ & 0.72 \\
\hline PAP mean, mmHg & $35[28-42]$ & 35 [28-42] & 35 [27-42] & 0.82 \\
\hline $\mathrm{CO}, \mathrm{L} / \mathrm{min}$ & $3.6[3.0-4.4]$ & $3.6[2.9-4.4]$ & $3.6[2.9-4.4]$ & 0.08 \\
\hline $\mathrm{Cl}, \mathrm{L} / \mathrm{min} / \mathrm{m}^{2}$ & $1.9[1.5-2.2]$ & $1.9[1.5-2.2]$ & $1.9[1.6-2.3]$ & 0.07 \\
\hline RVSWI, $\mathrm{g} / \mathrm{m}^{2} /$ beat & $6.7[5.1-9.3]$ & $6.3[4.6-8.9]$ & $6.9[5.2-9.4]$ & $<0.001$ \\
\hline SVR, Woods units & $18.2[14.2-23]$ & $17.9[13.6-23.4]$ & 15.7 [11.9-20.3] & $<0.001$ \\
\hline PVR, Woods units & $2.9[1.6-4.8]$ & $3.2[2.1-4.5]$ & $3.3[2-4.7]$ & 0.08 \\
\hline RA/PCWP & $0.46[0.33-0.65]$ & $0.45[0.32-0.63]$ & $0.52[0.38-0.75]$ & $<0.001$ \\
\hline PAPi & 2.4 [1.54-3.69] & $2.5[1.62-3.89]$ & $2[1.33-3.1]$ & $<0.001$ \\
\hline
\end{tabular}


Table 1 (continued)

\begin{tabular}{|c|c|c|c|c|}
\hline Variables & $\begin{array}{l}\text { Total population } \\
(N=2689)\end{array}$ & $\begin{array}{l}\text { Survivors } 90 \text { days } \\
(n=2202)\end{array}$ & $\begin{array}{l}\text { Non-survivors } 90 \text { days } \\
(n=487)\end{array}$ & $p$ value \\
\hline \multicolumn{5}{|l|}{ Echocardiographic } \\
\hline Severe RV dysfunction, $n(\%)$ & $257(10)$ & $179(8)$ & $78(16)$ & $<0.001$ \\
\hline TAPSE, $\mathrm{mm} / \mathrm{s}$ & $14[5-30]$ & $14[5-30]$ & $14[7-29]$ & 0.48 \\
\hline Moderate-to-severe tricuspid regurgitation, $n(\%)$ & $271(10)$ & $534(36)$ & $388(41)$ & 0.93 \\
\hline Moderate-to-severe mitral regurgitation, $n(\%)$ & $36(2)$ & $674(56)$ & $377(44)$ & 0.51 \\
\hline Moderate-to-severe aortic regurgitation, $n(\%)$ & $128(6)$ & $45(4)$ & $40(5)$ & 0.001 \\
\hline LV-EF grade $<20 \%, n(\%)$ & $1045(53)$ & $831(38)$ & $214(44)$ & 0.19 \\
\hline Main LVAD strategy & & & & $<0.001$ \\
\hline BTT (on the list) & $655(29)$ & $462(35)$ & $193(20)$ & \\
\hline BTC & $1001(44)$ & $573(44)$ & $428(45)$ & \\
\hline Destination therapy & $441(19)$ & $187(14)$ & $254(27)$ & \\
\hline Rescue therapy & $130(6)$ & $65(5)$ & $65(7)$ & \\
\hline BTR and others & $44(2)$ & $25(2)$ & $19(2)$ & \\
\hline \multicolumn{5}{|l|}{ LVAD device brand, $n$ (\%) } \\
\hline HeartMate II & $1167(43)$ & $1033(47)$ & $134(28)$ & $<0.001$ \\
\hline HeartMate 3 & $153(6)$ & $112(5)$ & $41(8)$ & $<0.001$ \\
\hline Heart Ware HVAD & $1369(51)$ & $1057(48)$ & $312(64)$ & 0.007 \\
\hline \multicolumn{5}{|l|}{ Surgical duration } \\
\hline CPB time, min & $86[65-15]$ & $86[64-113]$ & $91[61-133]$ & $<0.001$ \\
\hline Surgery time, min & 230 [180-285] & 225 [180-277] & 255 [193-330] & $<0.001$ \\
\hline
\end{tabular}

All continuous values are presented in mean \pm standard deviation unless stated otherwise or presented as median [IQR]. Categorical variables are stated as frequencies and percentages.

AST serum aspartate transaminase, IABP intra-aortic balloon pump, INTERMACS the Interagency Registry for Mechanically Assisted Circulatory Support (For INTERMACS classes. see text for details), $L V$ left ventricular, EF ejection fraction, $L V A D$ left ventricular assist device, VA-ECMO veno-arterial extracorporeal membrane oxygenator, NYHA New York Heart Association, PAP pulmonary artery pressure, PAPi pulmonary artery pulsatility index, $P C W P$ pulmonary capillary wedge pressure, PVR pulmonary vascular resistance, $R A$ right atrial, $R V$ right ventricular, $R V S W I$ right-ventricular stroke work index, TAPSE tricuspid annular plane systolic excursion, $B T T$ bridge to transplant, $B T C$ bridge to candidacy, BTR bridge to recovery, $C P B$ cardio pulmonary bypass

\section{Discussion}

To the best of our knowledge, this is the first and largest study to explore differential causes of death in the early (90 days) post-LVAD in Europe. Earlier Intermacs annual reports described an early rapidly falling hazard phase merges with a constant phase at approximately 3 months [22]. The main study findings are: (1) $18 \%$ of LVAD recipients died within 90 days following LVAD implantation; (2) MOF and sepsis followed by CPF and CVA are the most common causes of death in the early period; (5) A simple model of 12 variables predicted early mortality following LVAD implantation with a good discriminative power with area under the curve of 0.75 .

Independent clinical predictors of early death were age, female sex, INTERMACS profile 1 to 3, and ECMO. Laboratory predictors included elevated serum creatinine, total bilirubin, lactate, and low hemoglobin. Furthermore, hemodynamic predictors included elevated RAto-PCWP ratio, pulmonary vascular resistance, and low systemic vascular resistance. Longer total implantation time was also independent predictor of early mortality.
The common causes of death were MOF, CVA, and sepsis, followed by RHF and device malfunction in the early 90 days in the INTERMACS registry [22]. Among the three mainstream LVAD brands used in this study, CVA has been shown more frequently in HVAD compared with HMII [23]. Furthermore, the use of latest LVAD designs such as HM3 in the MOMENTUM 3 study was associated with less frequent thromboembolic complications than HMII $[24,25]$. In our study of EUROMACS Registry, the main causes of early death were MOF (36\%), sepsis $(28 \%)$, cardiopulmonary failure (CPF; 10\%), CVA (9\%), and right-sided heart failure (RHF, 8\%). Furthermore, MOF and sepsis are $70 \%$ of causes of death in the first week.

The cascade of RHF-induced cardiogenic shock, acute kidney failure, and MOF provokes high morbidity and mortality, including prolonged ICU stay and hospitalization. Congestion and/or ischemia of the gastrointestinal tract, particularly when associated with prolonged ICU stay, predisposes to bacterial translocation. In this study, $26 \%$ of deaths are due to sepsis with similar incidence in the early period following LVAD implantation. 


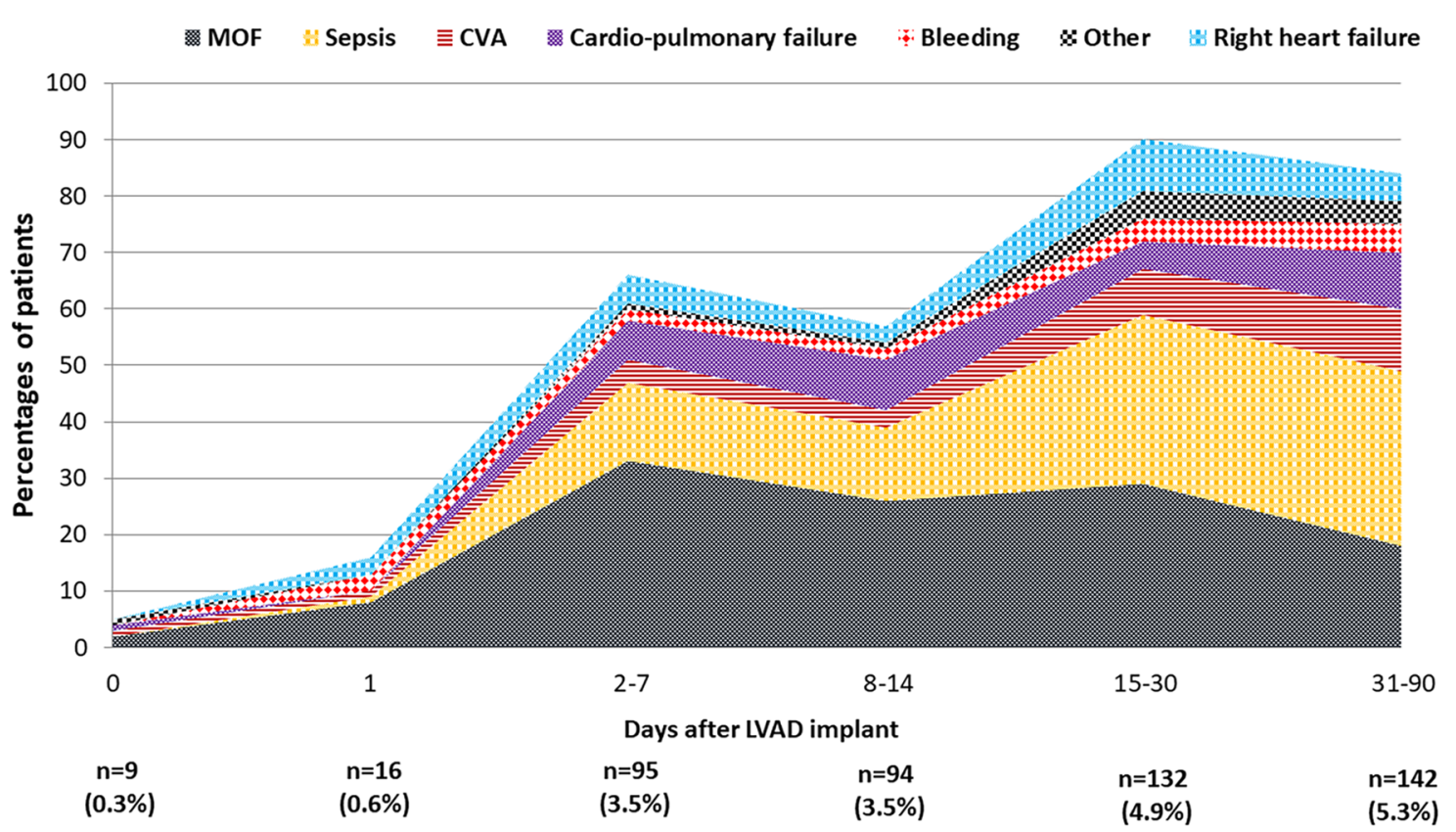

Fig. 2 Detailed time-based presentation of causes of death within 90 days following LVAD implantation in the EUROMACS registry. For abbreviations, see Fig. 1

Infections are either VAD-specific, VAD-related, and/or non-VAD infections. Despite improved care, driveline infections are associated with high morbidity and mortality [26-28]. As abovementioned, prolonged ICU stay is associated with increased risk of infection consequently impacting survival post-LVAD [14].

\section{Components of predicting early mortality}

In our study, the predictors for early post-LVAD mortality are: older age, female sex, sicker, hospitalized patients (INTERMACS profile 1 to 3 and having ECMO), impaired renal and hepatic function (serum creatinine and total bilirubin), prolonged tissue hypoxia (lactate), and low hemoglobin. Furthermore, hemodynamic predictors included elevated RA-to-PCWP ratio, pulmonary vascular resistance, and low systemic vascular resistance reflecting right-sided heart failure. Prolonged total implantation time is associated with early mortality.

Our findings confirm also the role of advanced age and female sex as predictors of increased early mortality following LVAD implantation [22, 29].

High RA/PCWP is a sign of RHF, mostly in combination with volume overload. Aggressive pre- and post-operative diuresis for euvolemia, prolonged postoperative inotropic support, pulmonary vasodilators (e.g., nitric oxide, inhaled prostacyclin), and, in selected case, temporary RVAD support could help to prevent further complications of severe RHF. Furthermore, elevated PVR is associated with increased early death. High PVR contribute to RV afterload and decreased RV function. If the pulmonary artery compliance does not improve rapidly, post-LVAD risk of RHF increases [14, $21,30]$. LVAD implantation will usually improve the RV function, the pulmonary and LV filling pressures. In the very, early post-operative phase, however, the RV needs time (probably $>10-14$ days) before physiological adaptation and recovery of the peri-operative hit of ischemia, distorted interventricular dependence, and volume overload will commence.

Our findings confirm that an advanced INTERMACS profile is associated with increased early mortality following LVAD implantation [31]. Patients with advanced INTERMACS profile are sicker, have a higher incidence of biventricular failure, suffer from severe hemodynamic derangement with imminent secondary organ / multiorgan failure [32]. However, in a recent trial, the early LVAD implantation in higher INTERMACS profiles (5-7) except for profile 4 failed to be superior to medical therapy, especially in terms of survival and quality of life [33].

Patients presenting with acute "crush and burn" need stabilization with a temporary MCS before commencing to a durable MCS. However, currently available temporary MCS, such as VA-ECMO, Impella, and IABP, in patients in INTERMACS 1 results in poor outcome post-LVAD and, therefore, yet to be further explored 
Table 2 Baseline univariate predictors of early mortality after LVAD implantation using continuous values

\begin{tabular}{|c|c|c|c|c|c|c|c|}
\hline Variables & $\begin{array}{l}\text { Coefficient } \\
\text { of regression }\end{array}$ & S.E & Wald & $p$ value & OR & $\begin{array}{l}\text { Lower } 95.0 \% \mathrm{Cl} \\
\text { for OR Lower }\end{array}$ & $\begin{array}{l}\text { Upper } 95.0 \% \mathrm{Cl} \\
\text { for OR Upper }\end{array}$ \\
\hline \multicolumn{8}{|l|}{ Demographics } \\
\hline Age, year & 0.023 & 0.004 & 29 & $<0.001$ & 1.023 & 1.015 & 1.032 \\
\hline Gender (female) & 0.224 & 0.126 & 3 & 0.076 & 1.251 & 0.977 & 1.602 \\
\hline Body surface area, $\mathrm{m}^{2}$ & -0.101 & 0.228 & 0.197 & 0.657 & 0.904 & 0.578 & 1.414 \\
\hline Body mass index, $\mathrm{kg} / \mathrm{m}^{2}$ & 0.006 & 0.006 & 0.844 & 0.358 & 1.006 & 0.994 & 1.017 \\
\hline Race (Caucasian) & 0.461 & 0.113 & 16.657 & $<0.001$ & 1.585 & 1.271 & 1.978 \\
\hline Ischemic aetiology & 0.204 & 0.105 & 3.786 & 0.052 & 1.226 & 0.999 & 1.505 \\
\hline Blood type O (reference) & & & & 0.202 & 1 & - & - \\
\hline Blood type A & 0.047 & 0.111 & 0.177 & 0.674 & 1.048 & 0.844 & 1.301 \\
\hline Blood type $A B$ & -0.212 & 0.232 & 0.833 & 0.361 & 0.809 & 0.513 & 1.275 \\
\hline Blood type B & -0.270 & 0.166 & 2.658 & 0.103 & 0.763 & 0.551 & 1.056 \\
\hline INTERMACS class (1-3 vs 4-7) & 0.732 & 0.129 & 32.06 & $<0.001$ & 2.078 & 1.613 & 2.677 \\
\hline IABP (yes vs no) & 0.374 & 0.158 & 5.581 & 0.018 & 1.454 & 1.066 & 1.984 \\
\hline VA-ECMO (yes or no) & 1.291 & 0.141 & 84.176 & $<0.001$ & 3.635 & 2.759 & 4.790 \\
\hline Use of vasopressors & 1.082 & 0.113 & 91.937 & $<0.001$ & 2.950 & 2.365 & 3.680 \\
\hline Use of inotropes $\geq 3$ & 0.6 & 0.134 & 19.891 & $<0.001$ & 1.821 & 1.399 & 2.371 \\
\hline \multicolumn{8}{|l|}{ Laboratory } \\
\hline Serum creatinine, $\mathrm{mol} / \mathrm{L}$ & 0.006 & 0.001 & 61.481 & 0.000 & 1.006 & 1.005 & 1.008 \\
\hline $\mathrm{BUN}, \mathrm{mg} / \mathrm{dL}$ & 0.008 & 0.001 & 3.117 & $<0.001$ & 1.008 & 1.006 & 1.011 \\
\hline AST U/L & 0.000 & 0.000 & 27.100 & $<0.001$ & 1.000 & 1.000 & 1.000 \\
\hline AST $>37 \mathrm{U} / \mathrm{L}$ & 0.776 & 0.111 & 48.53 & $<0.001$ & 2.173 & 1.747 & 2.704 \\
\hline LDH U/L & 0.000 & 0.000 & 1.138 & $<0.001$ & 1.000 & 1.000 & 1.000 \\
\hline $\mathrm{LDH}>445 \mathrm{U} / \mathrm{L}$ & 0.762 & 0.131 & 33.978 & $<0.001$ & 2.143 & 1.658 & 2.768 \\
\hline Total bilirubin, mg/dL & 0.254 & 0.032 & 63.348 & $<0.001$ & 1.289 & 1.211 & 1.372 \\
\hline WBC, 109/mL & 0.061 & 0.010 & 34.632 & $<0.001$ & 1.063 & 1.041 & 1.084 \\
\hline Platelets, 1000/mL & -0.004 & 0.001 & 35.907 & $<0.001$ & 0.996 & 0.994 & 0.997 \\
\hline Platelets > 138, 1000/mL & 0.921 & 0.119 & 59.427 & $<0.001$ & 2.512 & 1.987 & 3.175 \\
\hline INR & 0.264 & 0.060 & 19.253 & $<0.001$ & 1.302 & 1.157 & 1.465 \\
\hline PTT, sec & 0.008 & 0.002 & 14.361 & $<0.001$ & 1.009 & 1.004 & 1.013 \\
\hline Lactate, $\mathrm{mmol} / \mathrm{L}$ & 0.015 & 0.004 & 17.724 & $<0.001$ & 1.016 & 1.008 & 1.023 \\
\hline Albumin, mg/dL & -0.022 & 0.013 & 2.912 & 0.088 & 0.978 & 0.954 & 1.003 \\
\hline Hemoglobin, g/dL & -0.177 & 0.026 & 47.489 & $<0.001$ & 0.838 & 0.797 & 0.881 \\
\hline \multicolumn{8}{|l|}{ Hemodynamic } \\
\hline Heart rate, beats/min & 0.007 & 0.003 & 6.045 & 0.014 & 1.007 & 1.001 & 1.012 \\
\hline Heart rate $>100$ beats/min & 0.352 & 0.125 & 7.906 & 0.005 & 1.423 & 1.113 & 1.819 \\
\hline Diastolic BP, mmHg & -0.02 & 0.005 & 18.695 & $<0.001$ & 0.980 & 0.972 & 0.989 \\
\hline Systolic BP, mmHg & -0.006 & 0.003 & 3.361 & 0.067 & 0.994 & 0.988 & 1.000 \\
\hline RA pressure, $\mathrm{mmHg}$ & 0.062 & 0.009 & 48.111 & $<0.001$ & 1.064 & 1.045 & 1.083 \\
\hline PCWP, mmHg & 0.007 & 0.007 & 1.005 & 0.316 & 1.007 & 0.994 & 1.020 \\
\hline PAP systolic & -0.003 & 0.003 & 0.817 & 0.366 & 0.997 & 0.991 & 1.003 \\
\hline PAP diastolic & 0.002 & 0.005 & 0.132 & 0.716 & 1.002 & 0.992 & 1.012 \\
\hline PAP mean, mmHg & -0.001 & 0.005 & 0.053 & 0.817 & 0.999 & 0.990 & 1.008 \\
\hline PAPi & -0.126 & 0.027 & 21.731 & $<0.001$ & 0.882 & 0.837 & 0.930 \\
\hline $\mathrm{CO}, \mathrm{L} / \mathrm{min}$ & 0.075 & 0.043 & 3.013 & 0.083 & 1.078 & 0.990 & 1.174 \\
\hline $\mathrm{Cl}, \mathrm{L} / \mathrm{min} / \mathrm{m}^{2}$ & 0.142 & 0.079 & 3.235 & 0.072 & 1.153 & 0.987 & 1.346 \\
\hline RVSWI, g/m²/beat & -0.063 & 0.017 & 13.755 & $<0.001$ & 0.939 & 0.908 & 0.971 \\
\hline SVR, woods units & -0.038 & 0.008 & 21.820 & $<0.001$ & 0.963 & 0.948 & 0.978 \\
\hline PVR, woods units & 0.033 & 0.019 & 3.065 & 0.080 & 1.033 & 0.996 & 1.072 \\
\hline RA/PCWP & 0.648 & 0.139 & 21.753 & $<0.001$ & 1.912 & 1.456 & 2.511 \\
\hline
\end{tabular}


Table 2 (continued)

\begin{tabular}{|c|c|c|c|c|c|c|c|}
\hline Variables & $\begin{array}{l}\text { Coefficient } \\
\text { of regression }\end{array}$ & S.E & Wald & $p$ value & OR & $\begin{array}{l}\text { Lower } 95.0 \% \mathrm{Cl} \\
\text { for OR Lower }\end{array}$ & $\begin{array}{l}\text { Upper } 95.0 \% \text { CI } \\
\text { for OR Upper }\end{array}$ \\
\hline \multicolumn{8}{|l|}{ Echocardiographic } \\
\hline Severe RV dysfunction & 0.600 & 0.139 & 18.476 & $<0.001$ & 1.821 & 1.386 & 2.394 \\
\hline TAPSE, $\mathrm{mm} / \mathrm{s}$ & -0.011 & 0.016 & 0.499 & 0.480 & 0.989 & 0.959 & 1.020 \\
\hline Moderate or severe tricuspid regurgitation & 0.271 & 0.107 & 6.476 & 0.011 & 1.312 & 1.064 & 1.616 \\
\hline Moderate or severe tricuspid regurgitation & -0.030 & 0.168 & 0.032 & 0.857 & 0.970 & 0.699 & 1.348 \\
\hline Moderate or severe mitral regurgitation & 0.260 & 0.404 & 0.414 & 0.520 & 1.297 & 0.587 & 2.863 \\
\hline Moderate or severe aortic regurgitation & 0.686 & 0.200 & 11.732 & 0.001 & 1.986 & 1.341 & 2.941 \\
\hline LV-EF grade $<20 \%$ & 0.152 & 0.114 & 1.764 & 0.184 & 1.164 & 0.930 & 1.457 \\
\hline \multicolumn{8}{|l|}{ Operative and/or device variables } \\
\hline \multicolumn{8}{|l|}{ Main LVAD strategy } \\
\hline BTT (on the list) & & & 40.523 & $<0.001$ & Reference & & \\
\hline BTC & 0.286 & 0.140 & 4.173 & 0.041 & 1.331 & 1.012 & 1.752 \\
\hline Destination therapy & 0.806 & 0.156 & 26.605 & $<0.001$ & 2.238 & 1.648 & 3.040 \\
\hline Rescue therapy & 1.013 & 0.221 & 21.008 & $<0.001$ & 2.755 & 1.786 & 4.248 \\
\hline BTR and others & 0.843 & 0.357 & 5.585 & 0.018 & 2.324 & 1.155 & 4.678 \\
\hline \multicolumn{8}{|l|}{ Surgical duration } \\
\hline Surgery time, min & 0.003 & 0 & 50.574 & $<0.001$ & 1.003 & 1.002 & 1.004 \\
\hline
\end{tabular}

AST serum aspartate transaminase, IABP intra-aortic balloon pump, INTERMACS the Interagency Registry for Mechanically Assisted Circulatory Support (For INTERMACS classes. see text for details), $L V$ left ventricular, $L V A D$ left ventricular assist device, VA-ECMO veno-arterial extracorporeal membrane oxygenator, NYHA New York Heart Association, PAP pulmonary artery pressure, PAPi pulmonary artery pulsatility index, PCWP pulmonary capillary wedge pressure, $P V R$ pulmonary vascular resistance, $R A$ right atrial, $R V$ right ventricular, $R V S W I$ right-ventricular stroke work index, TAPSE tricuspid annular plane systolic excursion, $B T T$ bridge to transplant, $B T C$ bridge to candidacy, BTR bridge to recovery, CPB cardio pulmonary bypass

Table 3 Baseline multivariate predictors of early mortality after LVAD implantation using continuous values

\begin{tabular}{llll}
\hline Variables & OR & $\mathbf{9 5 . 0 \%}$ Cl for OR & $\boldsymbol{p}$ value \\
\hline Age (years) & 1.028 & $1.018-1.038$ & 0.000 \\
Gender (female) & 1.339 & $1.003-1.788$ & 0.048 \\
INTERMACS Class 1-3 & 1.5 & $1.121-2.007$ & 0.006 \\
ECMO & 1.989 & $1.431-2.765$ & 0.000 \\
Creatinine $\mu \mathrm{mol} / \mathrm{L}$ & 1.003 & $1.002-1.005$ & 0.000 \\
Total bilirubin g/dL & 1.193 & $1.116-1.275$ & 0.000 \\
Lactate mmol/L & 1.011 & $1.003-1.019$ & 0.008 \\
Hemoglobin g/dL & 0.908 & $0.858-0.961$ & 0.001 \\
RA/PCWP & 1.74 & $1.292-2.344$ & 0.000 \\
PVR woods unit & 1.089 & $1.044-1.135$ & 0.000 \\
SVR woods unit & 0.974 & $0.957-0.992$ & 0.004 \\
\hline Total implantation time (min) & 1.003 & $1.002-1.004$ & 0.000 \\
\hline
\end{tabular}

For abbreviations, see Table 1

[16]. Furthermore, patients with pre-operative impaired renal and hepatic function, or prolonged peripheral tissue hypoxia (lactate) have increased early mortality following LVAD implantation. We believe that proper timing of LVAD, earlier in the process of end-stage heart failure, before a full-blown cardiogenic shock, is critical in achieving a good survival chance. Furthermore,

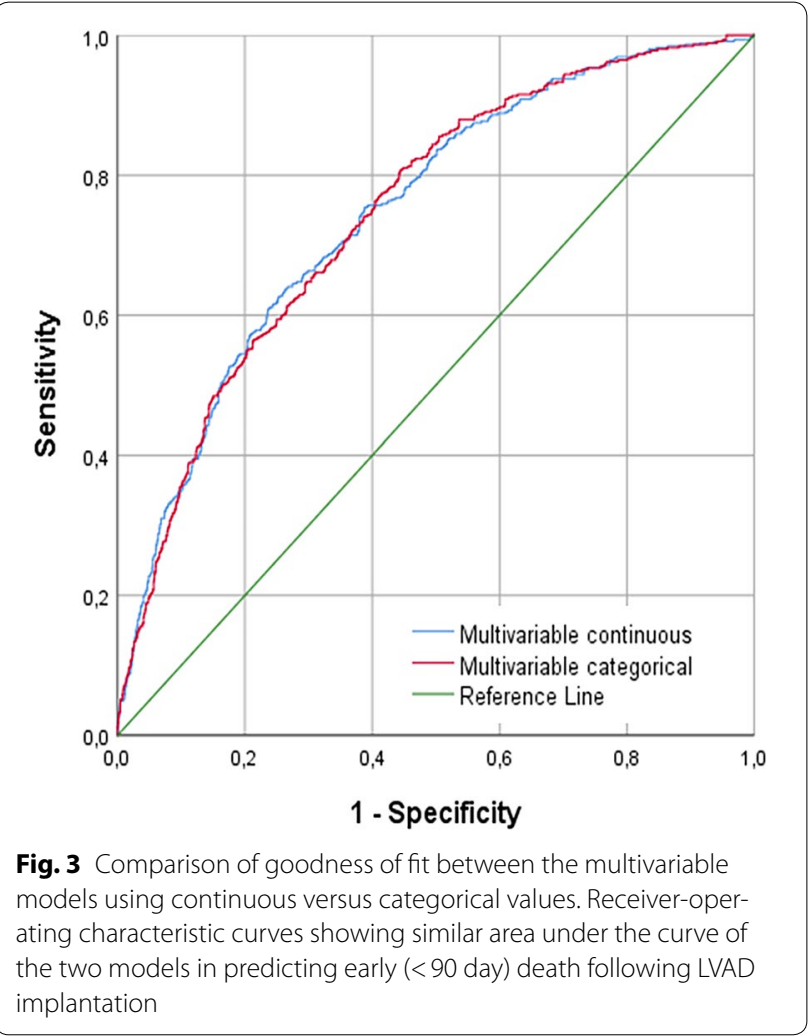


appropriate and timely management of the right ventricular failure, prevention of severe kidney failure, and multi-organ failure are essential for a successful LVAD implantation.

Low hemoglobin level is associated with increased early mortality. Anemia is found in about one-third of chronic HF patients, most commonly due to anemia of chronic disease and chronic renal failure. Also, impaired nutrition, malabsorption due to congestion, abnormal production of hepcidin, and reduced intracellular uptake of iron have been reported as causes of anemia in patients with HF $[34,35]$. Therefore, anemia might reflect the severity of the illness pre-LVAD.

Finally, prolonged time of LVAD surgery is associated with increased early mortality following LVAD implantation. This finding has been also shown in previous study by our group in which prolonged surgery time is associated with increased early right-sided heart failure complicating an ICU course [14].

\section{Clinical implications}

We found that the most common causes of death early post-LVAD are MOF, sepsis, and CPF. Patients dying early after LVAD implantation were older, often female, sicker (INTERMACS profile 1-3), suffering from preoperative anemia, impaired renal and liver function, and having signs of impending or evident RHF. Those patients with high RA/PCWP have probably already compromised RV function and higher risk of post-operative right-sided heart failure. It is known that half of ICU patients had a nosocomial infection and are, therefore, at a high risk for sepsis [36]. Furthermore, as abovementioned, congested gut has been identified as a source of infection and is a known sepsis triggering problem in ICU patients with MOF, due to translocation of gut flora into the bloodstream [36, 37].

Based on the two main causes of death in early postLVAD, MOF, and sepsis, we should encourage clinicians to prevent deterioration of the RV function. A tailored risk-based approach focused on prevention and timely management of pre- and post-operative RHF via pharmacological and/or temporary RVAD. A patient with a high risk for early mortality may benefit from early or prophylactically short-term mechanical circulatory support, and above all aggressive pre- and post-operative optimization of the right-sided fillings pressures. Second, early decision of LVAD implantation could select patients with less sicker patients, increasing INTERMACS profile and risk of secondary organ failure.

\section{Limitations}

There are several limitations that should be acknowledged in this study including the retrospective analysis.
Multi-national, multicenter registry like EUROMACS Registry without yet formal financial and manpower reimbursement from the national health authorities, insurance, the incomplete, has inherent shortcomings, like missing data. Several parameters were incompletely collected in the database. Therefore, we used multiple imputations to account for randomly missing data. However, this approach is based on strong assumptions that it is not possible to verify.

An another important limitation was also the retrospective analysis of the EUROMACS database. Another important limitation was the clinical judgment of the primary cause of death by which in case of multi-organ failure or sepsis was based on clinician's own decision per site. Similarly, cardiopulmonary failure, which contains left heart failure, lung failure, pulmonary artery embolization, and myocardial infarction, could be used in different way from the centers with underspecifying diseases like acute respiratory distress syndrome (ARDS) as lung failure. Furthermore, without a central core laboratory analysis of the imaging data, it is presumptuous that all data are analyzed in accordance with the published guidelines. However, the site initiation/audit and the protocol of the EUROMACS registry require that the site investigators to perform their analysis according to the published guidelines.

\section{Conclusions}

In the European Registry for Patients with Mechanical Circulatory Support, approximately one out of five patients died within 90 days following LVAD implantation. Early mortality is primarily dominated by multiorgan failure followed by sepsis. A simple model comprises 12 variables predicts early mortality following LVAD implantation with a good discriminative power of an area under the curve of 0.75 .

\section{Electronic supplementary material}

The online version of this article (https://doi.org/10.1007/s00134-020-05939-1) contains supplementary material, which is available to authorized users.

\section{Abbreviations \\ APTT: Activated partial thromboplastin time; BTC: Bridge to candidacy; BTT: Bridge to transplant; Cl: Confidence interval; CVA: Cerebro-vascular accident; DT: Destination therapy; ECMO: Extracorporeal membrane oxygenation; EUROMACS: The European Registry for Patients with Mechanical Circulatory Support; IABP: Intra-aortic balloon pump; ICU: Intensive-care unit; INTERMACS: The Interagency Registry for Mechanically Assisted Circulatory Support; LV: Left ventricle/ventricular; LVAD: Left ventricular assist device; MOF: Multiorgan failure; HR: Hazard ratio; RHF: Right-sided heart failure; RV: Right ventricle/ ventricular.}

\section{Author details}

${ }^{1}$ Thoraxcenter, Department of Cardiology, Erasmus MC University Medical Centre Rotterdam, Dr. Molewaterplein 40, 3015 GD, Rotterdam, The Netherlands. ${ }^{2}$ Department of Intensive Care, Haga Teaching Hospital, The Hague, The Netherlands. ${ }^{3}$ Department of Cardiology, College of Medicine, Nursing 
and Health Sciences, National University of Ireland Galway, Saolta University Healthcare Group, Galway University Road, Galway, Ireland. ${ }^{4}$ EUROMACS Registry, EACTS, Windsor, UK. ${ }^{5}$ Amsterdam University Medical Centers-University of Amsterdam, Amsterdam, The Netherlands. ${ }^{6}$ Cardialysis, Academic Research Organisation Rotterdam, Rotterdam, The Netherlands. ${ }^{7}$ Department of Cardiothoracic and Vascular Surgery, German Heart Center Berlin, DZHK (German Centre for Cardiovascular Research), Berlin, Germany. ${ }^{8}$ Department of Cardiac Surgery, University Hospital Leuven, University of Leuven, Leuven, Belgium. ${ }^{9}$ Department for Thoracic and Cardiovascular Surgery, Heart and Diabetes Centre NRW, Ruhr-University Bochum, Bad Oeynhausen, Germany. ${ }^{10}$ Department of Cardiovascular Surgery, University Hospital Zurich, Zurich, Switzerland.

\section{Acknowledgements}

For a full list of contributors to EUROMACS, please see the supplementary appendix I.

\section{Author contributions}

Study concept and design: Akin, Soliman, and Caliskan. Akin, Soliman, de By, Muslem, and Caliskan had full access to all the data in the study and take responsibility for the integrity of the data and the accuracy of the data analysis. Acquisition, analysis, or interpretation of data: Akin, Soliman, de By, Muslem, Schoennrath, Gummert, Meyns, Mohacsi, and Caliskan. Drafting of the manuscript: Akin, Soliman, de By, Muslem, and Caliskan. Critical revision of the manuscript for important intellectual content: all authors. Statistical analysis: Akin, Soliman, Muslem, Caliskan, and Tijssen. Administrative, technical, or material support: de By, Gummert, and Caliskan. Study supervision: Caliskan.

\section{Compliance with ethical standards}

\section{Conflicts of interest}

The authors declare that they have no conflicts of interest.

\section{Open Access}

This article is licensed under a Creative Commons Attribution-NonCommercial 4.0 International License, which permits any non-commercial use, sharing, adaptation, distribution and reproduction in any medium or format, as long as you give appropriate credit to the original author(s) and the source, provide a link to the Creative Commons licence, and indicate if changes were made. The images or other third party material in this article are included in the article's Creative Commons licence, unless indicated otherwise in a credit line to the material. If material is not included in the article's Creative Commons licence and your intended use is not permitted by statutory regulation or exceeds the permitted use, you will need to obtain permission directly from the copyright holder.To view a copy of this licence, visit http://creativecommons.org/licen ses/by-nc/4.0/.

\section{Publisher's Note}

Springer Nature remains neutral with regard to jurisdictional claims in published maps and institutional affiliations.

Received: 18 May 2019 Accepted: 13 January 2020 Published online: 3 February 2020

\section{References}

1. Starling RC, Estep JD, Horstmanshof DA, Milano CA, Stehlik J, Shah KB, Bruckner BA, Lee S, Long JW, Selzman CH et al (2017) Risk assessment and comparative effectiveness of left ventricular assist device and medical management in ambulatory heart failure patients: the roadmap study 2-year results. JACC Heart Fail 5(7):518-527

2. Kirklin JK, Naftel DC, Pagani FD, Kormos RL, Stevenson LW, Blume ED, Miller MA, Baldwin JT, Young JB (2014) Sixth INTERMACS annual report: a 10,000-patient database. J Heart Lung Transplant 33(6):555-564

3. Slaughter MS, Rogers JG, Milano CA, Russell SD, Conte JV, Feldman D, Sun B, Tatooles AJ, Delgado RM 3rd, Long JW et al (2009) Advanced heart failure treated with continuous-flow left ventricular assist device. N Engl J Med 361(23):2241-2251

4. Mehra MR, Naka Y, Uriel N, Goldstein DJ, Cleveland JC Jr, Colombo PC, Walsh MN, Milano CA, Patel CB, Jorde UP et al (2017) A fully magnetically levitated circulatory pump for advanced heart failure. N Engl I Med 376(5):440-450

5. Dang NC, Topkara VK, Mercando M, Kay J, Kruger KH, Aboodi MS, Oz MC, Naka Y (2006) Right heart failure after left ventricular assist device implantation in patients with chronic congestive heart failure. J Heart Lung Transplant 25(1):1-6

6. Patil NP, Mohite PN, Sabashnikov A, Dhar D, Weymann A, Zeriouh M, Hards R, Hedger M, De Robertis F, Bahrami T et al (2015) Preoperative predictors and outcomes of right ventricular assist device implantation after continuous-flow left ventricular assist device implantation. J Thorac Cardiovasc Surg 150(6): 1651-1658

7. Rich JD, Gosev I, Patel CB, Joseph S, Katz JN, Eckman PM, Lee S, Sundareswaran K, Kilic A, Bethea B et al (2016) The incidence, risk factors, and outcomes associated with late right-sided heart failure in patients supported with an axial-flow left ventricular assist device. J Heart Lung Transplant 2016.

8. Yoshioka D, Sakaguchi T, Saito S, Miyagawa S, Nishi H, Yoshikawa Y, Fukushima S, Saito T, Daimon T, Ueno T et al (2012) Predictor of early mortality for severe heart failure patients with left ventricular assist device implantation: significance of INTERMACS level and renal function. Circ J 76(7):1631-1638

9. Bansal N, Hailpern SM, Katz R, Hall YN, Tamura MK, Kreuter W, O'Hare AM (2017) Outcomes associated with left ventricular assist devices among recipients with and without end-stage renal disease. JAMA Intern Med 2017.

10. Kavarana MN, Pessin-Minsley MS, Urtecho J, Catanese KA, Flannery M, Oz MC, Naka Y (2002) Right ventricular dysfunction and organ failure in left ventricular assist device recipients: a continuing problem. Ann Thorac Surg 73(3):745-750

11. Craig ML (2011) Management of right ventricular failure in the era of ventricular assist device therapy. Curr Heart Fail Rep 8(1):65-71

12. Akin S, Soliman Oll, Muslem R, Miranda D, Reis D, Den Uil CA, Constantinescu AA, Kardys I, Bogers A, Zijlstra F (2017) Preoperative right heart hemodynamics predict right heart failure and early ICU mortality following LVAD implantation. In: European heart journal: 2017: Oxford Univ Press Great Clarendon St, Oxford Ox2 6dp, England; 2017: 1044-1044.

13. de By TM, Mohacsi P, Gummert J, Bushnaq H, Krabatsch T, Gustafsson F, Leprince P, Martinelli L, Meyns B, Morshuis M et al (2015) The European Registry for Patients with Mechanical Circulatory Support (EUROMACS): first annual report. Eur J Cardiothorac Surg 47(5):770-776; discussion 776-777

14. Soliman Oll, Akin S, Muslem R, Boersma E, Manintveld OC, Krabatsch T, Gummert JF, de By T, Bogers A, Zijlstra F et al (2018) Derivation and Validation of a novel right-sided heart failure model after implantation of continuous flow left ventricular assist devices: The EUROMACS (European Registry for Patients with Mechanical Circulatory Support) right-sided heart failure risk score. Circulation 137(9):891-906

15. Mcllvennan CK, Grady KL, Matlock DD, Helmkamp LJ, Abshire M, Allen LA (2019) End of life for patients with left ventricular assist devices: Insights from INTERMACS. J Heart Lung Transplant 38(4):374-381

16. Boyle AJ, Ascheim DD, Russo MJ, Kormos RL, John R, Naka Y, Gelijns AC, Hong KN, Teuteberg JJ (2011) Clinical outcomes for continuous-flow left ventricular assist device patients stratified by pre-operative INTERMACS classification. J Heart Lung Transplant 30(4):402-407

17. Lang RM, Badano LP, Mor-Avi V, Afilalo J, Armstrong A, Ernande L, Flachskampf FA, Foster E, Goldstein SA, Kuznetsova T et al (2015) Recommendations for cardiac chamber quantification by echocardiography in adults: an update from the American Society of Echocardiography and the European Association of Cardiovascular Imaging. Eur Heart J Cardiovasc Imaging 16(3):233-270

18. Lancellotti P, Tribouilloy C, Hagendorff A, Popescu BA, Edvardsen T, Pierard LA, Badano L, Zamorano JL (2013) Scientific document committee of the european association of cardiovascular I: recommendations for the echocardiographic assessment of native valvular regurgitation: an executive summary from the European Association of Cardiovascular Imaging. Eur Heart J Cardiovasc Imaging 14(7):611-644

19. Lancellotti P, Tribouilloy C, Hagendorff A, Moura L, Popescu BA, Agricola E, Monin JL, Pierard LA, Badano L, Zamorano JL et al (2010) European Association of Echocardiography recommendations for the assessment of valvular regurgitation. Part 1: aortic and pulmonary regurgitation (native valve disease). Eur J Echocardiogr 11(3):223-244. 
20. Lancellotti P, Moura L, Pierard LA, Agricola E, Popescu BA, Tribouilloy C, Hagendorff A, Monin JL, Badano L, Zamorano JL et al (2010) European Association of Echocardiography recommendations for the assessment of valvular regurgitation. Part 2: mitral and tricuspid regurgitation (native valve disease). Eur J Echocardiogr 11(4):307-332.

21. Morine KJ, Kiernan MS, Pham DT, Paruchuri V, Denofrio D, Kapur NK (2016) Pulmonary artery pulsatility index is associated with right ventricular failure after left ventricular assist device surgery. J Card Fail 22(2):110-116

22. Kirklin JK, Pagani FD, Kormos RL, Stevenson LW, Blume ED, Myers SL, Miller MA, Baldwin JT, Young JB, Naftel DC (2017) Eighth annual INTERMACS report: Special focus on framing the impact of adverse events. J Heart Lung Transplant 36(10):1080-1086

23. Rogers JG, Pagani FD, Tatooles AJ, Bhat G, Slaughter MS, Birks EJ, Boyce SW, Najjar SS, Jeevanandam V, Anderson AS et al (2017) Intrapericardial left ventricular assist device for advanced heart failure. N Engl J Med 376(5):451-460

24. Heatley G, Sood P, Goldstein D, Uriel N, Cleveland J, Middlebrook D, Mehra MR, Investigators M (2016) Clinical trial design and rationale of the Multicenter Study of MagLev Technology in Patients Undergoing Mechanical Circulatory Support Therapy With HeartMate 3 (MOMENTUM 3) investigational device exemption clinical study protocol. J Heart Lung Transplant 35(4):528-536

25. Mehra MR, Uriel N, Naka Y, Cleveland JC Jr, Yuzefpolskaya M, Salerno CT, Walsh MN, Milano CA, Patel CB, Hutchins SW et al (2019) A fully magnetically levitated left ventricular assist device: final report. N Engl J Med 380(17):1618-1627

26. Goldstein DJ, Naftel D, Holman W, Bellumkonda L, Pamboukian SV, Pagani FD, Kirklin J (2012) Continuous-flow devices and percutaneous site infections: clinical outcomes. J Heart Lung Transplant 31(11):1151-1157

27. Koval CE, Thuita L, Moazami N, Blackstone E (2014) Evolution and impact of drive-line infection in a large cohort of continuous-flow ventricular assist device recipients. J Heart Lung Transplant 33(11):1164-1172

28. Tong MZ, Smedira NG, Soltesz EG, Starling RC, Koval CE, Porepa L, Moazami N (2015) Outcomes of heart transplant after left ventricular assist device specific and related infection. Ann Thorac Surg 100(4):1292-1297
29. DeFilippis EM, Truby LK, Garan AR, Givens RC, Takeda K, Takayama H, Naka Y, Haythe JH, Farr MA, Topkara VK (2019) Sex-related differences in use and outcomes of left ventricular assist devices as bridge to transplantation. JACC Heart Fail 7(3):250-257

30. Meineri M, Van Rensburg AE, Vegas A (2012) Right ventricular failure after LVAD implantation: prevention and treatment. Best Pract Res Clin Anaesthesiol 26(2):217-229

31. Alba AC, Rao V, Ivanov J, Ross HJ, Delgado DH (2009) Usefulness of the INTERMACS scale to predict outcomes after mechanical assist device implantation. J Heart Lung Transplant 28(8):827-833

32. Stevenson LW, Pagani FD, Young JB, Jessup M, Miller L, Kormos RL, Naftel DC, Ulisney K, Desvigne-Nickens P, Kirklin JK (2009) INTERMACS profiles of advanced heart failure: the current picture. J Heart Lung Transplant 28(6):535-541

33. Shah KB, Starling RC, Rogers JG, Horstmanshof DA, Long JW, Kasirajan V, Stehlik J, Chuang J, Farrar DJ, Estep JD et al (2018) Left ventricular assist devices versus medical management in ambulatory heart failure patients: an analysis of INTERMACS Profiles 4 and 5 to 7 from the ROADMAP study. J Heart Lung Transplant 37(6):706-714

34. Anand IS (2008) Anemia and chronic heart failure implications and treatment options. J Am Coll Cardiol 52(7):501-511

35. Clark AL, Cleland JG (2005) Anemia and chronic heart failure: are we asking the right questions? Circulation 112(12):1681-1683

36. Vincent JL, Bihari DJ, Suter PM, Bruining HA, White J, Nicolas-Chanoin MH, Wolff M, Spencer RC, Hemmer M (1995) The prevalence of nosocomial infection in intensive care units in Europe. Results of the European Prevalence of Infection in Intensive Care (EPIC) Study. EPIC International Advisory Committee. JAMA 274(8):639-644.

37. Aslam S, Xie R, Cowger J, Kirklin JK, Chu VH, Schueler S, de By T, Gould K, Morrissey O, Lund LH et al (2018) Bloodstream infections in mechanical circulatory support device recipients in the International Society of Heart and Lung Transplantation Mechanically Assisted Circulation Support Registry: epidemiology, risk factors, and mortality. J Heart Lung Transplant 37(8):1013-1020 